06

\title{
Рентгеноструктурный анализ
}

\section{эпитаксиальных слоев со свойствами дислокационного фильтра}

\author{
() И.Д. Лошкарев, А.П. Василенко, Е.М. Труханов, \\ А.В. Колесников, М.О. Петрушков, М.А. Путято
}

Институт физики полупроводников им. А.В. Ржанова СО РАН, Новосибирск, Россия

E-mail: idl@isp.nsc.ru

Поступило в Редакцию 18 декабря 2017 г.

Продемонстрирован подход к экспресс-диагностике эпитаксиальных пленок с резким снижением плотности прорастающих дислокаций. Использован метод высокоразрешающей рентгеновской дифрактометрии, в частности картирование обратного пространства. Проведен структурный анализ гетеросистем $\mathrm{GaAs} / \mathrm{Si}(001)$ с низкотемпературными слоями GaAs. Зарегистрировано снижение плотности прорастающих дислокаций в пленке GaAs с образованием малоугловой границы.

DOI: 10.21883/PJTF.2018.13.46323.17160

В мировой практике выращивания эпитаксиальных полупроводниковых гетероструктур получили распространение так называемые дислокационные фильтры, на которых происходит резкое снижение плотности прорастающих дислокаций (ПД) и улучшение структурного качества пленки [1-3]. Такую пленку можно рассматривать в виде двух слоев: нижний с большой плотностью трехмерной дислокационной сетки, верхний с малой плотностью. Неразрушающая экспресс-диагностика таких (как минимум двухслойных) гетеросистем с практически одинаковым параметром решетки, но сильно различающимся качеством слоев - непростая задача. Методом рентгеновской дифрактометрии, используя симметричный рефлекс, чаще всего получают лишь интегральную характеристику качества всей пленки в среднем по толщине, что не позволяет судить о распределении дефектов. Нами реализован подход, позволяющий дать характеристику структуры каждого из двух слоев с малым несоответствием между ними. Подход основан на ана- 


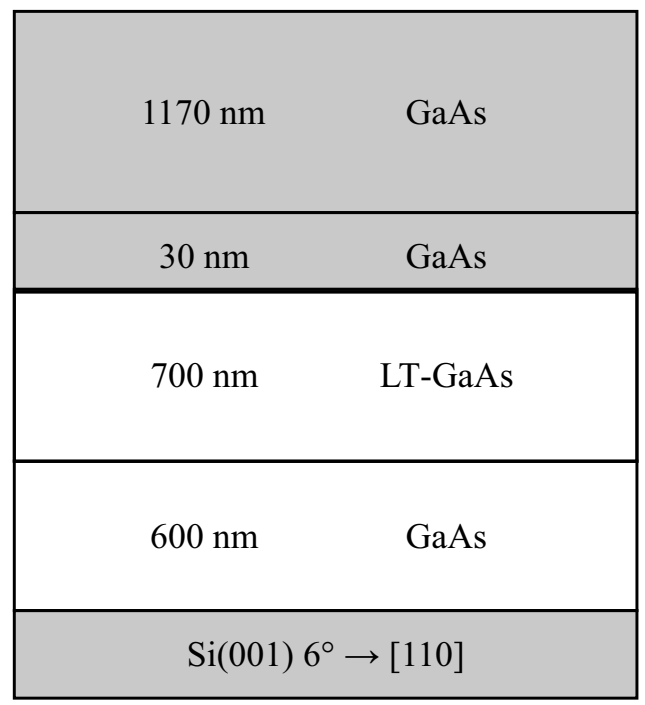

Рис. 1. Схема структуры пленки GaAs на вицинальной подложке $\mathrm{Si}(001)$. Верхний и нижний слои пленки разделены границей LT-GaAs/GaAs, показанной жирной линией.

лизе формы узла обратной решетки кристалла пленки на отклоненной кремниевой подложке.

Исследования проводились методом трехкристальной рентгеновской дифрактометрии высокого разрешения (HRXRD). Первичный пучок дифрактометра формировался рентгеновской трубкой с медным анодом, германиевым кристаллом-монохроматором в положении симметричного отражения (004) и выходной щелью коллиматора с размером $0.1 \mathrm{~mm}$ в плоскости дифракции. В качестве анализатора рассеянного излучения использовался кристалл $\mathrm{Si}$ с прорезным каналом, рефлекс (111).

Структуры $\mathrm{GaAs} / \mathrm{Si}(001)$ выращивались в установке молекулярнолучевой эпитаксии [4]. Формирование слоя зарождения осуществлялось методом атомно-слоевой эпитаксии: по 20 монослоев $\mathrm{GaP}$ и $\mathrm{GaAs}$ при температурах 330 и $260^{\circ} \mathrm{C}$ соответственно. Далее создана композиция, преимущественно состоящая из толстых низкотемпературных

Письма в ЖТФ, 2018, том 44, вып. 13 
слоев LT-GaAs $\left(200^{\circ} \mathrm{C}\right)$. Будем называть ее нижним слоем пленки (рис. 1) с суммарной толщиной $1300 \mathrm{~nm}$. Верхний слой пленки $\mathrm{GaAs}$ $\left(600^{\circ} \mathrm{C}\right)$ толщиной $1200 \mathrm{~nm}$ содержит тонкий переходный слой GaAs $\left(350^{\circ} \mathrm{C}\right)$.

Выращивание слоя LT-GaAs нацелено на снижение плотности ПД [4]. При росте низкотемпературного GaAs происходит избыточный захват As, что приводит к увеличению параметра решетки пленки [5]. Ожидается, что слой LT-GaAs среди слоев высокотемпературного GaAs будет выступать в роли дислокационного фильтра. На верхней границе раздела LT-GaAs/GaAs возникают напряжения несоответствия противоположного знака, под действием которых ПД изгибаются и формируют участки дислокаций несоответствия (ДН) в указанной границе раздела. Аналогичный механизм безактивационного образования участков ДН от прорастающей из подложки дислокации описывал Мэтьюз [6]. Преимущество безактивационного процесса состоит в том, что не требуется накопления большой энергии упругих деформаций, а в случае малого несоответствия это имеет ключевое значение. Уже при росте переходного слоя $\mathrm{GaAs}\left(350^{\circ} \mathrm{C} / 30 \mathrm{~nm}\right)$ прорастающие участки дислокаций, изгибаясь, могут активно перемещаться в латеральном направлении, аннигилируя с другими дислокациями. Таким образом, увеличивается вероятность аннигиляции ПД на границе раздела LT-GaAs/GaAs. Отметим, что во время роста верхнего слоя GaAs $\left(600^{\circ} \mathrm{C} / 1170 \mathrm{~nm}\right)$ слой LT-GaAs практически подвергается отжигу, в процессе которого приобретает естественный параметр решетки GaAs.

Измерение степени релаксации пленки на вицинальной поверхности осложняется разворотом кристаллических решеток пленок относительно подложки в процессе релаксации. Как правило, наблюдается разворот пленки вокруг оси [011], которая совпадает с направлением вицинальных ступеней подложки. Разворот пленки (малоугловую границу) формирует сетка ДН с несбалансированной проекцией краевой составляющей векторов Бюргерса на нормаль к границе раздела [7]. Экспериментально наблюдались повороты пленок $\mathrm{A}_{3} \mathrm{~B}_{5}$ на отклоненных подложках как в сторону увеличения, так и в сторону уменьшения вицинального угла на величину до $1500 \operatorname{arcsec}$ [7-10]. При неполной релаксации пленки ее кристаллическая решетка искажена в общем случае триклинно, что характеризуется сдвиговыми углами. Для определения сдвиговых углов и измерения степени релаксации нами была разработана модель триклинных искажений [11], которая требует

Письма в ЖТФ, 2018, том 44, вып. 13 

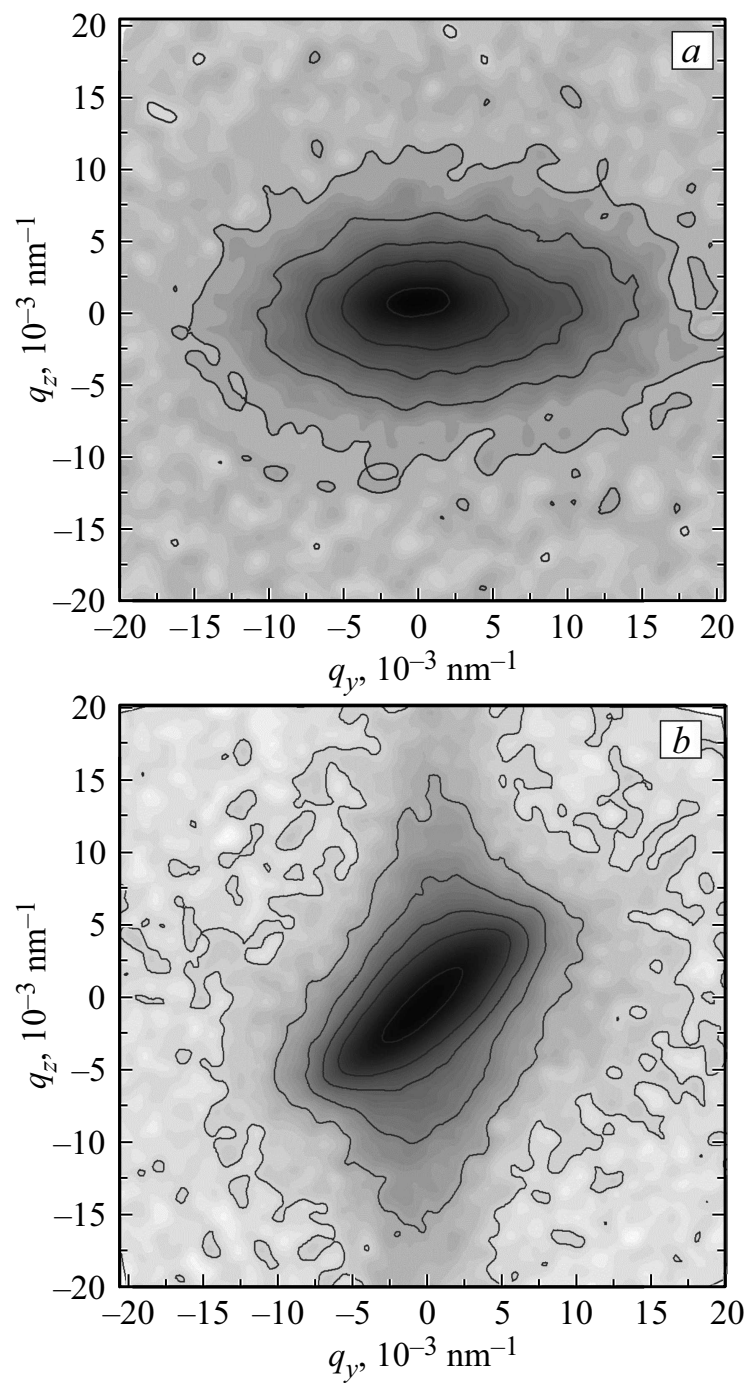

Рис. 2. Карты обратного пространства пленки GaAs. $a-$ узел (004), $b-$ узел $(\overline{2} \overline{2} 4), c$ - узел (224), $d-$ схема узла (224). 

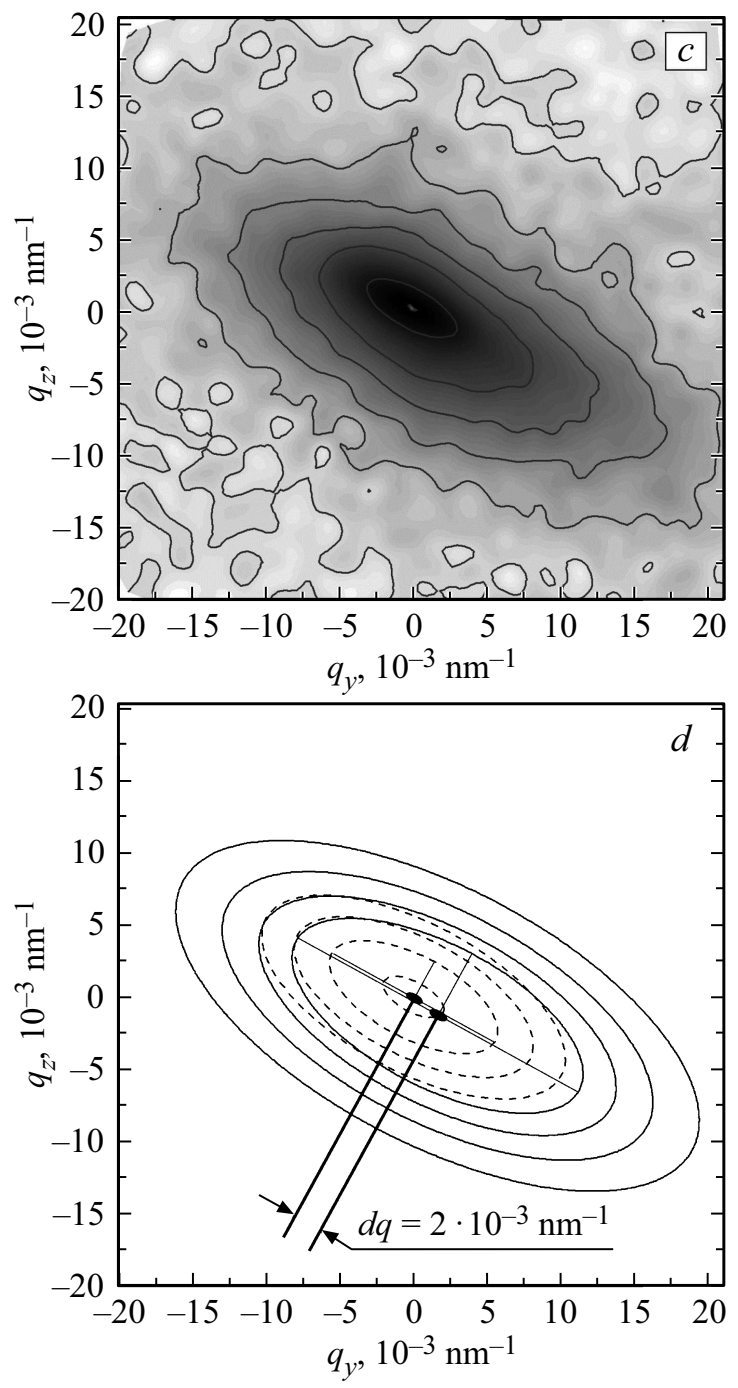

Рис. 2 (продолжение). 
записи не менее четырех кривых дифракционного отражения. Такой вариант анализа относительно прост с точки зрения эксперимента, однако неприменим для систем с малым несоответствием $(<0.2 \%)$ и/или малым разворотом $(<100 \operatorname{arcsec})$. Совместный анализ набора из нескольких узлов обратной решетки гетеросистемы дает возможность охарактеризовать близкие по параметру, но различные по структурному качеству слои.

На картах (рис. 2) представлены узлы обратной решетки пленки GaAs одной из гетеросистем. Узлы на всех картах вытянуты вдоль окружности вокруг нулевого узла (линия ориентаций), что свидетельствует о наличии ориентационных искажений в пленке изза присутствия ДН. Узлы (004) и (224) (рис. 2, a и c) имеют явно асимметричное распределение интенсивности. Максимум каждого из них смещен относительно центра внешних изолиний вдоль линии ориентаций против часовой стрелки. Такая форма узла вызвана наложением одного на другой узлов решеток верхнего и нижнего слоев. Размеры узлов различаются, отражая тем самым степень совершенства кристаллической решетки каждого из слоев. Узел $(\overline{2} \overline{2} 4)$, представленный на рис. 2, $b$, относительно узок и не имеет явной асимметрии, однако видны тяжи в вертикальном направлении, формирующие так называемый образ среза кристалла (crystal truncation rod). Глубина экстинкции брэгговского отражения от плоскостей $(\overline{2} \overline{2} 4)$ (угол входа $<1^{\circ}$ ) равна $280 \mathrm{~nm}$, что в 5.5 раза меньше, чем для (224) (угол входа $\left.12.8^{\circ}\right)-1550 \mathrm{~nm}$. Величины глубины экстинкции приведены для идеального кристалла, в реальном кристалле с дефектами они больше, но качественно соотношение величин сохраняется. Можно сделать заключение, что картина (рис. $2, b$ ) сформирована лишь верхним слоем пленки GaAs. Верхний слой GaAs общей толщиной около $1200 \mathrm{~nm}$ (рис. 1) интегрально более качествен, чем нижний слой GaAs суммарной толщиной $1300 \mathrm{~nm}$. На кривой дифракционного отражения в рефлексе (004) полная ширина на полувысоте пика составляет 170 arcsec.

Двумерной функцией Гаусса (two-dimensional Gaussian function) выполнена аппроксимация узкого пика от верхнего слоя и широкого пика от нижнего (рис. $2, d$ ). В результате определены координаты узлов в обратном пространстве для узла GaAs (224) с точностью $10^{-4} \mathrm{~nm}^{-1}$, что соответствует погрешности определения угла поворота $1.2 \mathrm{arcsec}$ и параметра решетки $3 \cdot 10^{-5} \mathrm{~nm}$. Рассмотрение узла всей пленки в

Письма в ЖТФ, 2018, том 44, вып. 13 


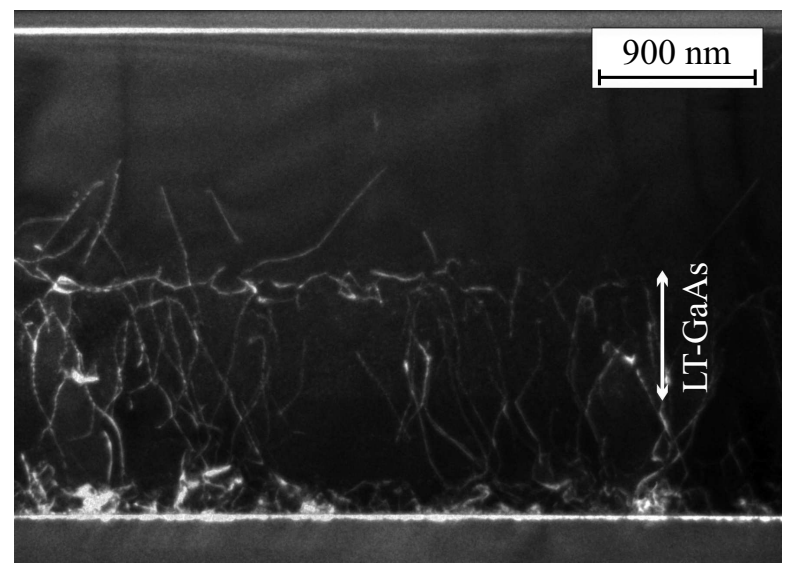

Рис. 3. ПЭМ-изображение поперечного среза структуры $2.5 \mu \mathrm{m} \mathrm{GaAs} / \mathrm{Si}(001)$ со слоями LT-GaAs.

виде суперпозиции двух узлов от верхнего и нижнего слоев позволило измерить смещение в обратном пространстве $d q=2 \cdot 10^{-3} \mathrm{~nm}^{-1}$ вдоль линии ориентаций и рассчитать угол разворота $\psi=25$ arcsec. Зарегистрированный разворот кристаллических решеток слоев относительно друг друга создан сеткой ДН, которая сформировалась в результате аннигиляции прорастающих участков дислокаций вблизи границы раздела LT-GaAs/GaAs.

Определение параметра решетки пленки, степени релаксации и величины разворота требует обработки как минимум двух карт обратного пространства. В нашем случае для расчета использованы рефлексы $(\overline{2} \overline{2} 4)$ и (224) (рис. $2, b$ и $c$ ). По положению узлов GaAs в обратном пространстве относительно узла подложки $\mathrm{Si}$ (на картах не приведен ввиду ограничений масштаба) определено, что оба слоя пленки полностью релаксированы. Развороты нижнего и верхнего слоев относительно подложки составляют 185 и $210 \operatorname{arcsec}$ в сторону увеличения вицинального угла соответственно.

Дополнением рентгеноструктурного анализа является результат просвечивающей электронной микроскопии (ПЭМ). На рис. 3 представлено ПЭМ-изображение поперечного среза обсуждаемой гетеросисте-

Письма в ЖТФ, 2018, том 44, вып. 13 
мы. Видно резкое уменьшение плотности прорастающих дислокаций на верхней границе слоя LT-GaAs. Также в этой границе раздела можно увидеть присутствие горизонтальных участков дислокаций, которые являются дислокациями несоответствия.

С помощью рентгеновской дифрактометрии показано резкое уменьшение плотности прорастающих дислокаций в пленке GaAs на вицинальной подложке Si. Аннигиляция ПД прошла преимущественно на верхней границе раздела LT-GaAs/GaAs c образованием участков ДН. Сетка дислокаций сформировала малоугловую границу, поворачивающую решетку на $\sim 25 \operatorname{arcsec}$. Продемонстрировано применение способа неразрушающей экспресс-диагностики гетероструктур, в которых для снижения плотности прорастающих дислокаций используется слой LT-GaAs, выступающий в качестве дислокационного фильтра.

Работа выполнена при поддержке Российского фонда фундаментальных исследований (грант № 16-32-60087 мол_а_дк).

Авторы выражают благодарность А.К. Гутаковскому за предоставление данных просвечивающей электронной микроскопии.

\section{Список литературы}

[1] Dey S., Joshi S., Garcia-Gutierrez D., Chaumont M., Campion A., JoseYacaman M., Banerjee S.K. // J. Electron. Mater. 2006. V. 35. P. 1607-1612.

[2] Jung D., Callahan P.G., Shin B., Mukherjee K., Gossard A.C., Bowers J.E. // J. Appl. Phys. 2017. V. 122. P. 225703.

[3] Mukhopadhyay P., Kumar R., Ghosh S., Chakraborty A., Bag A., Kabi S., Banerji P., Biswas D. // J. Cryst. Growth. 2015. V. 418. P. 138-144.

[4] Petrushkov M.O., Putyato M.A., Gutakovsky A.K., Preobrazhenskii V.V., Loshkarev I.D., Emelyanov E.A., Semyagin B.R., Vasev A.V. // J. Phys.: Conf. Ser. 2016. V. 741. P. 012020.

[5] Yu K.M., Kaminska M., Liliental-Weber Z. // J. Appl. Phys. 1992. V. 72. P. 2850 2856.

[6] Matthews J.W. // Phil. Mag. 1966. V. 13. P. 1207-1221.

[7] Takagi Y., Furukawa Y., Wakahara A., Kan H. // J. Appl. Phys. 2010. V. 107. P. 063506.

[8] Лошкарев И.Д., Василенко А.П., Труханов Е.М., Колесников А.В., Путято М.А., Есин М.Ю., Петрушков М.О. // Письма в ЖТФ. 2017. Т. 43. В. 4. C. 64-71. 
[9] Лошкарев И.Д., Василенко А.П., Труханов Е.М., Колесников А.В., Путято М.А., Семягин Б.Р., Преображсенский В.В., Пчеляков О.П. // Изв. РАН. Сер. физ. 2013. Т. 77. № 3. С. 264-267.

[10] Suzuki H., Sasaki T., Takahasi M., Ohshita Y., Kojima N., Kamiya I., Fukuyama A., Ikari T., Yamaguchi M. // Jpn. J. Appl. Phys. 2017. V. 56. P. 08MA06.

[11] Колесников А.В., Ильин А.С., Труханов Е.М., Василенко А.П., Лошкарев И.Д., Дерябин А.С. // Изв. РАН. Сер. физ. 2011. Т. 75. № 5. С. 652-655.

Письма в ЖТФ, 2018, том 44, вып. 13 